\title{
Responses of Castanopsis tribuloides and Pinus kesiya seedlings to mycelial inoculation of Russula alboareolata and Amanita princeps
}

\author{
Somchit Youpensuk ${ }^{1,2 *}$, Suwimon Wanwaen ${ }^{1}$ \\ ${ }^{1}$ Department of Biology, Faculty of Science, Chiang Mai University, Chiang Mai 50200, Thailand \\ ${ }^{2}$ Center of Excellence in Bioresources for Agriculture, Industry and Medicine, Department of Biology, Faculty of Science, \\ Chiang Mai University, Chiang Mai 50200, Thailand
}

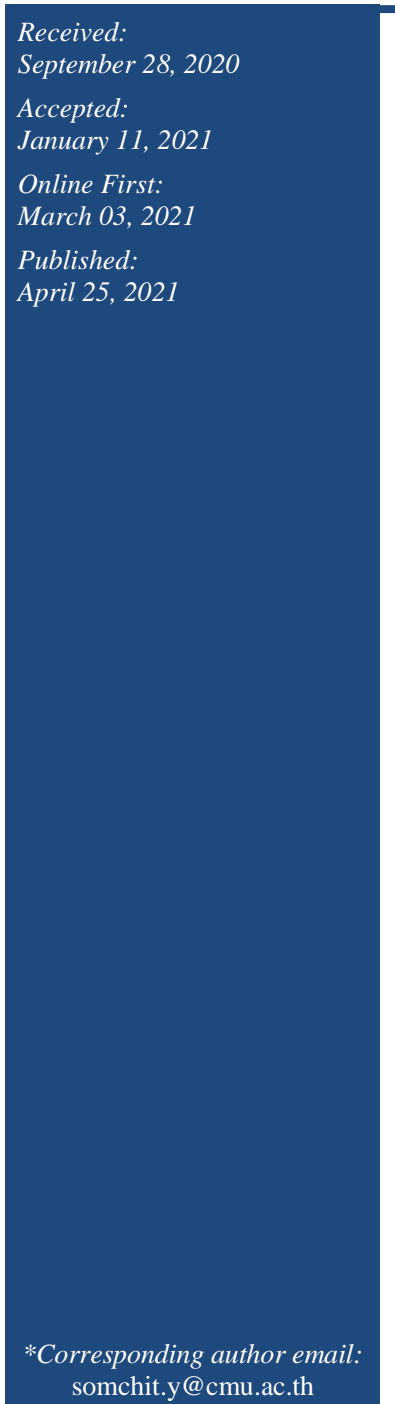

\begin{abstract}
Castanopsis tribuloides and Pinus kesiya are ectomycorrhizal (ECM) host plants. They are used for reforestation in degraded forestlands in northern Thailand. Objective of this research was to compare the effects of mycelial inoculation of Russula alboareolata and Amanita princeps, edible ECM mushrooms, on $C$. tribuloides and $P$. kesiya seedlings by evaluating ECM formation, growth response and nutrient accumulation. The study period was from 2018 to 2020. Two-month old seedlings of $C$. tribuloides and $P$. kesiya were inoculated with mycelium slurries of $R$. alboareolata and A. princeps. The effects of the ECM fungi on the host plants were evaluated at six months after inoculation. ECM roots of $C$. tribuloides associated with $R$. alboareolata and $A$. princeps were irregularly pinnate, whereas ECM roots of $P$. kesiya inoculated with the fungi were dichotomous branching patterns. Survivals of $C$. tribuloides seedlings in the uninoculated, $R$. alboareolata and A. princeps treatments were 66.7, 76.7 and $97.2 \%$ respectively. Survivals of $P$. kesiya seedlings in both the uninoculated and inoculated treatments were about $95 \%$. Inoculation with the ECM fungi significantly increased the growth and nutrient accumulations of $C$. tribuloides and $P$. kesiya seedlings. The increase in dry weight was greater for inoculated plants of $C$. tribuloides than for those of $P$. kesiya. For $C$. tribuloides, the increase was significantly greater for plants inoculated with $R$. alboareolata than for those inoculated with $A$. princeps. For $P$. kesiya, there was no difference in the increase in dry weight between plants inoculated with each of the fungal species. Seedlings of $C$. tribuloides and $P$. kesiya associated with the edible ECM fungi may be beneficial for reforestation.
\end{abstract}

Keywords: Ectomycorrhizas, Edible mushrooms, Fagaceae, Pinaceae

\section{How to cite this:}

Youpensuk S and Wanwaen S, 2021. Responses of Castanopsis tribuloides and Pinus kesiya seedlings to mycelial inoculation of Russula alboareolata and Amanita princeps. Asian J. Agric. Biol. 2021(2): 202009503. DOI: https://doi.org/10.35495/ajab.2020.09.503

This is an Open Access article distributed under the terms of the Creative Commons Attribution 3.0 License. (https://creativecommons.org/licenses/by/3.0), which permits unrestricted use, distribution, and reproduction in any medium, provided the original work is properly cited. 


\section{Introduction}

Forests are natural resources of plants, animals and other forest products. In recent years, many forest areas have decreased. Replanting has significantly contributed to restore the forest ecosystems. Castanopsis tribuloides )Sm.) A.DC. (Fagaceae) is one of framework tree species for forest replanting in degraded tropical forestlands in northern Thailand (Blakesley et al., 2002). C. tribuloides is a mediumsized, evergreen tree, up to $18 \mathrm{~m}$ tall. Seeds of $C$. tribuloides are edible (Forest Restoration Research Unit, 2000). Pinus kesiya Royle ex. Gordon (Pinnaceae) is a pioneer species preferred for reforestation on highland sites in Thailand (Fern, 2014). C. tribuloides and $P$. kesiya are widely distributed in the mixed evergreen and deciduous forest, the evergreen forest, and the mixed evergreen and pine forest in the tropical regions of Asia (Forest Restoration Research Unit, 2000; Schmidt and Nguyen, 2004; Fern, 2014). Both $C$. tribuloides and $P$. kesiya are ectomycorrhizal (ECM) host plants.

Mycelia of ECM fungi around roots of the host plants increase the absorptive areas of rooting systems of the plants, thereby increasing the uptake of mineral elements (Dosskey et al., 1990; Finlay, 2004). The $\mathrm{ECM}$ fungi, in turn, receive nutrients from photosynthesis of the host plants (Dosskey et al., 1990; Brundrett et al., 1996). This interaction of ECM fungi with roots of the host plants typically have beneficial effects on growth of the host plants (Smith and Read, 1997). However, the response of the host plants to ECM formation depends on the suitability of the ECM fungi to the host plants and environment. Most ECM fungi need host plants to stimulate the production of fruiting bodies (Ohta and Fujiwara, 2003; Sanmee et al., 2010). Russula alboareolata Hongo and Amanita princeps Corner \& Bas are edible gilled ECM mushrooms, they belong to the orders Russulales and Agaricales, respectively. Their fruiting bodies provide food for human and wild animals. The ECM mushrooms are collected for food and sold by local villagers during rainy seasons in Thailand (Chandrasrikul et al., 2008). Forest trees may be colonized by indigenous ECM fungi that may be edible or poisonous mushrooms. Therefore, it is beneficial to use seedlings associated with known edible ECM fungi before planting in forests. The objectives of this research were to compare the effects of mycelial inoculation of $R$. alboareolata and $A$. princeps on mycorrhization of $C$. tribuloides and
$P$. kesiya seedlings, and to evaluate subsequent survival, growth and mineral nutrition of the host plants in a greenhouse.

\section{Material and Methods}

Isolation and inoculum production of $R$. alboareolata and A. princeps

Basidiocarps of $R$. alboareolata and A. princeps were collected from the forest at Doi Suthep-Pui National Park in Chiang Mai province, Thailand. Isolates of $R$. alboareolata and $A$. princeps obtained aseptically from tissues inside basidiocarps were placed on modified Melin Norkans (MMN) agar (Marx, 1969) at $\mathrm{pH} 6$ in Petri dishes. The culture plates were incubated in the dark at $28^{\circ} \mathrm{C}$ for one month. Fivemm-diameter plugs of hyphae from pure cultures of $R$. alboareolata and A. princeps were subcultured on MMN agar supplemented with $1.0 \mathrm{~g} / \mathrm{L}$ yeast extract in $9 \mathrm{~cm}$ Petri dishes and incubated in the dark at $28^{\circ} \mathrm{C}$ for one month to increase mycelia of the fungi. For inoculum production, the mycelia from colony edges of each species were cut and inoculated in MMN broth supplemented with $1.0 \mathrm{~g} / \mathrm{L}$ yeast extract at $\mathrm{pH} 6$ in Erlenmeyer flasks. The culture flasks were incubated on a reciprocal shaker at $130 \mathrm{rpm}$ for two months at room temperature $\left(28-32^{\circ} \mathrm{C}\right)$ and in the dark. After that, mycelial inocula of $R$. alboareolata and $A$. princeps were fragmented in sterilized blenders for $10 \mathrm{~s}$.

\section{Seedling preparation}

Seeds of $C$. tribuloides and $P$. kesiya were washed and surface sterilized by immersing in $0.6 \% \mathrm{NaOCl}$ for $5 \mathrm{~min}$ and in $70 \%$ ethanol for $30 \mathrm{~s}$. Then, the seeds were washed in sterile water three times. The surface-sterilized seeds of $C$. tribuloides and $P$. kesiya were sown in trays containing a sterilized mixture of soil, peat and sand (2:1:1, v/v) and placed in a greenhouse. The seeds were watered once daily for germination of the seeds and then the growth of the seedlings.

Inoculation of the hyphae of the ECM fungi to $C$. tribuloides and $P$. kesiya seedlings

Two-month-old seedlings of $C$. tribuloides and $P$. kesiya were transferred to $1000 \mathrm{~g}$ sterilized soil in the growing bag $(8 \times 18 \mathrm{~cm})$ with one plant per bag. The soil used in this experiment $(\mathrm{pH} 5.5)$ had $7.19 \%$ organic matter, $0.36 \%$ total nitrogen, $8.24 \mathrm{mg} / \mathrm{kg}$ 
available phosphorus, $280.00 \mathrm{mg} / \mathrm{kg}$ exchangeable potassium, $82.50 \mathrm{mg} / \mathrm{kg}$ exchangeable calcium, 34.14 $\mathrm{mg} / \mathrm{kg}$ exchangeable magnesium and $26.46 \mathrm{mg} / \mathrm{kg}$ extractable sulfur. Treatments were applied to the culture medium before planting. The ECM treatments consisted of $20 \mathrm{~mL}$ of the mycelial inoculum slurry added to each hole made to receive a seedling. The uninoculated plants were treated with $20 \mathrm{~mL}$ of the culture medium without fungal mycelium. Seedlings inoculated with the ECM fungi and uninoculated treatments of $C$. tribuloides and $P$. kesiya were replicated 30 times. The seedlings were placed in a greenhouse and watered once daily.

\section{Evaluation of ECM formations and the growth of C. tribuloides and $P$. kesiya seedlings}

At six months after transplanting, seedlings of $C$. tribuloides and $P$. kesiya were measured for height (with a ruler at the soil line to the height of the stem) and stem diameter (with a pair of callipers at one $\mathrm{cm}$ above root collar). Roots of $C$. tribuloides and $P$. kesiya seedlings were carefully washed. Shoots of $C$. tribuloides and $P$. kesiya seedlings were separated from roots. The proportion of ECM roots in the root samples was estimated for the percentage of root length colonization by the gridline intersection method according to Brundrett et al. (1996). Shoots and roots were dried at $60^{\circ} \mathrm{C}$ for 2 days before weighing to evaluate the shoot and root dry weights. The dried shoots of $C$. tribuloides and $P$. kesiya seedlings were also evaluated for the contents of nitrogen $(\mathrm{N})$ by the Kjeldahl method, phosphorus $(\mathrm{P})$ by the dry ashing and molybdovanado-phosphoric acid method and potassium (K) by the dry ashing and atomic absorption spectrophotometer method. The percentage of increased growth associated with mycorrhizal colonization was calculated as the following formula: [(Total dry weight of inoculated plant - Total dry weight of uninoculated plant)/Total dry weight of inoculated plant] $\times 100$.

\section{Statistical analysis}

Data were analyzed by analysis of variance (ANOVA). SPSS program 23.0 for Windows was used to conduct the ANOVA. Significant differences were determined to compare means of the treatments at $p \leq 0.05$ with Duncan's Multiple Range Test. The period of this research was performed from 2018 to 2020 .

\section{Results}

\section{Mycelia of $R$. alboareolata and A. princeps}

Hyphae of $R$. alboareolata were pale brown, without clamp connections. Hyphae of $A$. princeps were white, and the hyphae have clamp connections. Colonies of $R$. alboareolata on MMN agar supplemented with $1.0 \mathrm{~g} / \mathrm{L}$ yeast extract were whitish cream to pale brown (Fig. 1a). Colonies of $A$. princeps were white on MMN agar supplemented with $1.0 \mathrm{~g} / \mathrm{L}$ yeast extract (Fig. 1b).
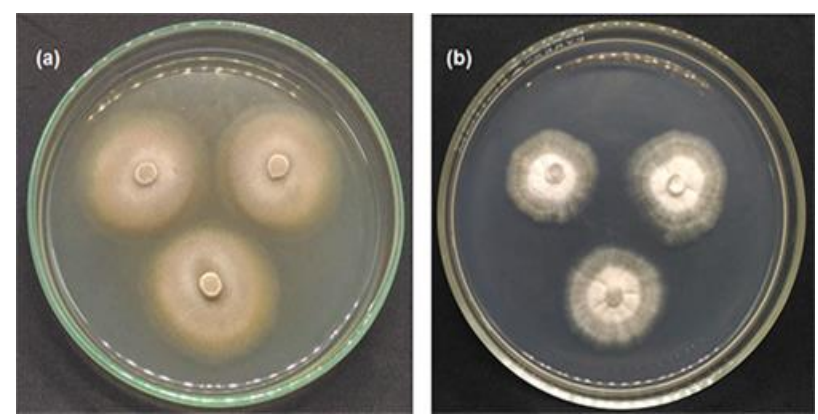

Figure-1. Colonies of Russula alboareolata (a) and Amanita princeps (b) cultured on MMN agar supplemented with $1.0 \mathrm{~g} / \mathrm{L}$ yeast extract

\section{Associations between roots of the host plants and} the ECM fungi

All seedlings of $C$. tribuloides and $P$. kesiya inoculated with $R$. alboareolata and A. princeps formed ECM roots, while roots of the uninoculated seedlings were not found to have ECM roots and easily dry after harvesting (Fig. 2a and Fig. 3a).

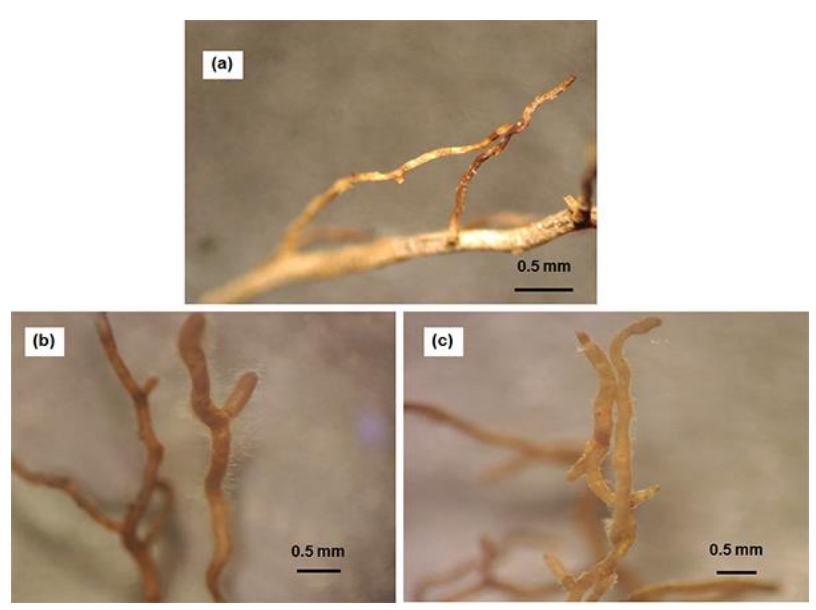

Figure-2. Roots of Castanopsis tribuloides seedlings (a) non-ectomycorrhizal roots, (b) ectomycorrhizal (ECM) roots inoculated with Russula alboareolata, and (c) ECM roots inoculated with Amanita princeps 


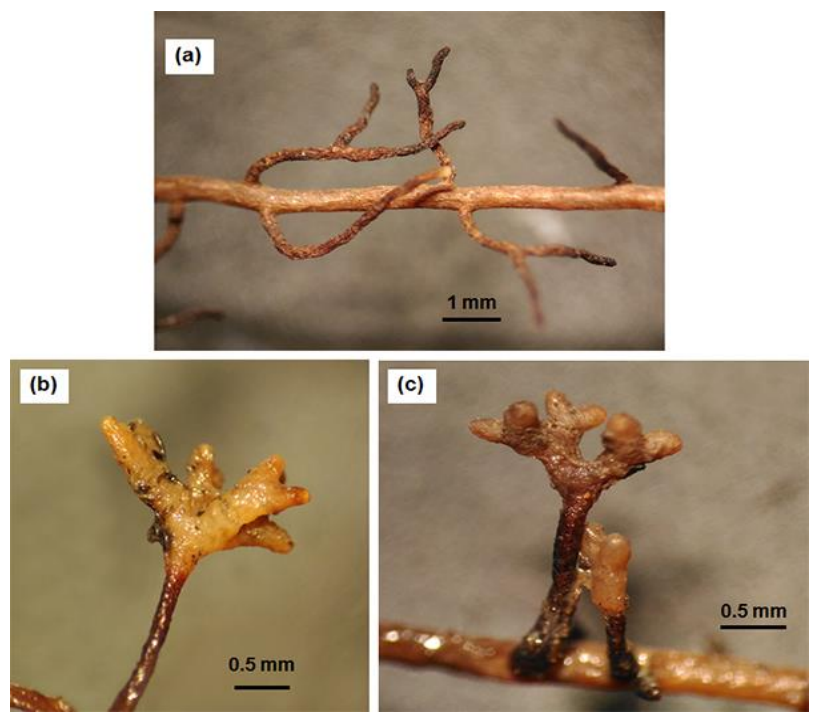

Figure-3. Roots of Pinus kesiya seedlings

(a) non-ectomycorrhizal roots, (b) ectomycorrhizal (ECM) roots inoculated with Russula alboareolata, and (c) ECM roots inoculated with Amanita princeps

Branching patterns of the ECM roots of $C$. tribuloides associated with $R$. alboareolata and $A$. princeps were irregular pinnate (Fig. 2b and Fig. 2c). Branching patterns of ECM roots of $P$. kesiya associated with the ECM fungi were dichotomous (Fig. 3b and Fig. 3c). Root length colonizations of $C$. tribuloides seedlings inoculated with $R$. alboareolata and A. princeps were $30.2 \%$ and $29.8 \%$ respectively. Root length colonizations of $P$. kesiya seedlings inoculated with $R$. alboareolata and $A$. princeps were $19.9 \%$ and $18.9 \%$ respectively. Inoculation with $R$. alboareolata and $A$. princeps significantly increased survival of $C$. tribuloides seedlings. Survival of $C$. tribuloides seedlings of the uninoculated treatment, inoculated with $R$. alboareolata and A. princeps treatments were $66.7 \%, \quad 76.7 \%$ and $97.2 \%$ respectively. Whereas both of the inoculated and uninoculated treatments of $P$. kesiya seedlings survived about $95 \%$ (Table 1).

Table-1. Survival of Castanopsis tribuloides and Pinus kesiya seedlings

\begin{tabular}{|l|c|c|}
\hline \multirow{2}{*}{ ECM fungi } & \multicolumn{2}{c|}{ Survival of seedlings (\%) } \\
\cline { 2 - 3 } & C. . tribuloides & P. kesiya \\
\hline None & $66.7^{\mathrm{c}}$ & $94.5^{\mathrm{a}}$ \\
\hline R. alboareolata & $76.7^{\mathrm{b}}$ & $95.4^{\mathrm{a}}$ \\
\hline A. princeps & $97.2^{\mathrm{a}}$ & $95.0^{\mathrm{a}}$ \\
\hline
\end{tabular}

The means in the same column with different letters are significantly different $(p \leq 0.05)$.
Growth of $\boldsymbol{C}$. tribuloides and $\boldsymbol{P}$. kesiya seedlings

Heights, stem diameters and dry weights of both $C$. tribuloides and $P$. kesiya seedlings inoculated with $R$. alboareolata and $A$. princeps were significantly higher than those of the uninoculated seedlings (Table 2, Fig. 4 and Fig. 5). The increase in dry weight was greater for ECM-inoculated seedlings of $C$. tribuloides than for those of $P$. kesiya. The increase was significantly greater for $C$. tribuloides seedlings inoculated with $R$. alboareolata than inoculated with $A$. princeps. The percentage of increased growth of $C$. tribuloides seedlings inoculated with $R$. alboareolata and A. princeps compared with the uninoculated treatment were $86.8 \%$ and $82.4 \%$, respectively. For $P$. kesiya, there was no difference in the increase in dry weight between plants inoculated with each of the fungal species. The percentage of increased growth of $P$. kesiya seedlings inoculated with $R$. alboareolata and A. princeps compared with the uninoculated treatment were $44.8 \%$ and $42.6 \%$, respectively.

Table-2. Heights and stem diameters of Castanopsis tribuloides and Pinus kesiya seedlings

\begin{tabular}{|c|c|c|c|c|}
\hline \multirow{2}{*}{ ECM fungi } & \multicolumn{2}{|c|}{ Height (cm) } & \multicolumn{2}{c|}{ Stem diameters (mm) } \\
\cline { 2 - 5 } & C. tribuloides & $\boldsymbol{P}$. kesiya & C. tribuloides & $\boldsymbol{P}$. kesiya \\
\hline None & $21.3 \pm 5.96^{\mathrm{b}}$ & $17.9 \pm 2.48^{\mathrm{b}}$ & $2.7 \pm 0.51^{\mathrm{b}}$ & $2.3 \pm 0.30^{\mathrm{b}}$ \\
\hline R. alboareolata & $64.2 \pm 7.64^{\mathrm{a}}$ & $21.4 \pm 3.66^{\mathrm{a}}$ & $5.3 \pm 0.79^{\mathrm{a}}$ & $3.0 \pm 0.54^{\mathrm{a}}$ \\
\hline A. princeps & $58.9 \pm 16.28^{\mathrm{a}}$ & $20.8 \pm 2.47^{\mathrm{a}}$ & $5.6 \pm 0.80^{\mathrm{a}}$ & $3.0 \pm 0.48^{\mathrm{a}}$ \\
\hline
\end{tabular}

Means \pm standard error of the means in the same column with different letters are significantly different $(p \leq 0.05)$.

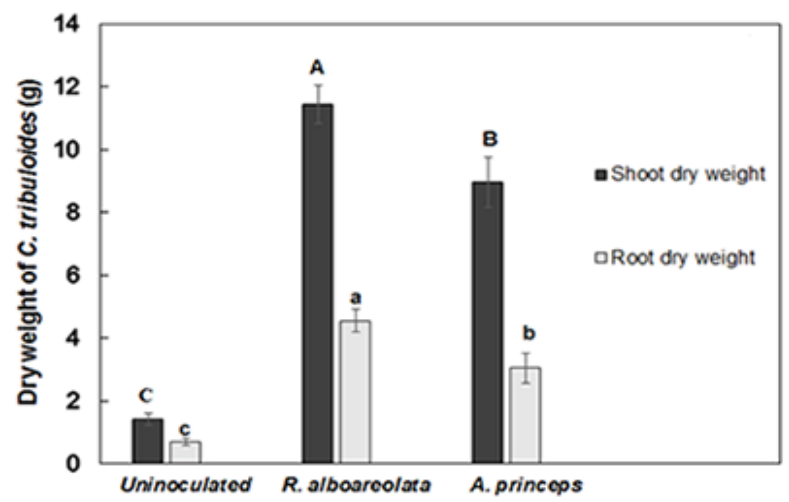

Figure-4. Shoot and root dry weights of Castanopsis tribuloides seedlings

Shoot dry weights with different capital letters and root dry weights with different lower-case letters are significantly different $(p \leq 0.05)$ of the means with \pm standard error of the means. 


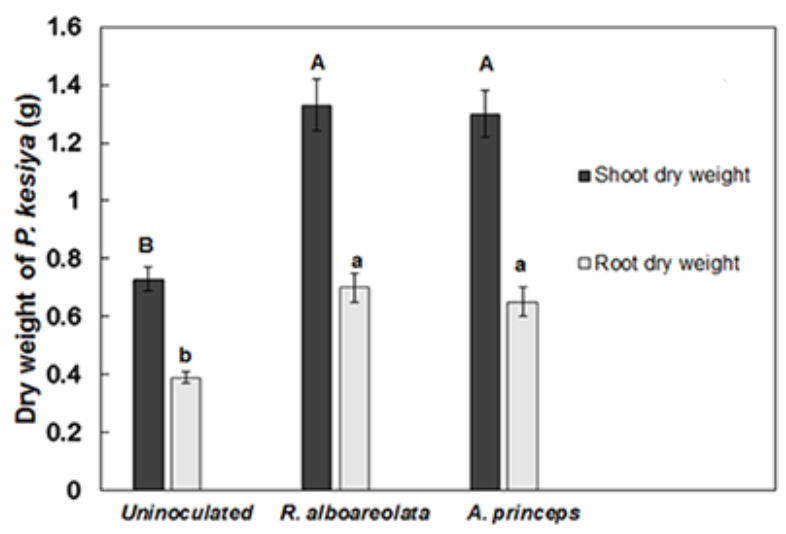

Figure-5. Shoot and root dry weights of Pinus kesiya seedlings

Shoot dry weights with different capital letters and root dry weights with different lower-case letters are significantly different $(p \leq 0.05)$ of the means with \pm standard error of the means.

\section{Nutrient contents of $C$. tribuloides and $P$. kesiya seedlings}

The $C$. tribuloides and $P$. kesiya seedlings inoculated with $R$. alboareolata and $A$. princeps had shoot $\mathrm{N}, \mathrm{P}$ and $\mathrm{K}$ contents significantly higher than those of the uninoculated seedlings. However, accumulations of $\mathrm{P}$ and K contents of $C$. tribuloides seedlings inoculated with $R$. alboareolata were significantly higher than those of $C$. tribuloides seedlings inoculated with $A$. princeps (Table 3 ). The N, $\mathrm{P}$ and K contents of the $P$. kesiya seedlings inoculated with $R$. alboareolata and A. princeps were not significantly different between species of the ECM fungi (Table 4).

Table-3. Nutrient accumulations (mg/plant) in shoots of Castanopsis tribuloides seedlings

\begin{tabular}{|c|c|c|c|}
\hline ECM fungi & N content & P content & K content \\
\hline None & $20.69 \pm 1.06^{\mathrm{b}}$ & $1.40 \pm 0.08^{\mathrm{c}}$ & $12.41 \pm 0.72^{\mathrm{c}}$ \\
\hline R. alboareolata & $80.95 \pm 2.96^{\mathrm{a}}$ & $11.52 \pm 0.48^{\mathrm{a}}$ & $109.43 \pm 11.43^{\mathrm{a}}$ \\
\hline A. princeps & $77.02 \pm 8.42^{\mathrm{a}}$ & $7.89 \pm 0.78^{\mathrm{b}}$ & $86.00 \pm 5.98^{\mathrm{b}}$ \\
\hline
\end{tabular}

Means \pm standard error of the means in the same column with different letters are significantly different $(p \leq 0.05)$.

The P contents of $C$. tribuloides seedlings inoculated with $R$. alboareolata and A. princeps were about 8.2 and 5.6 times that of the uninoculated $C$. tribuloides seedlings, respectively. The $\mathrm{K}$ accumulations in the $C$. tribuloides seedlings inoculated with $R$. alboareolata and A. princeps were about 8.8 and 6.9 times that of the uninoculated $C$. tribuloides seedlings, respectively. While the $\mathrm{N}$ contents of $C$. tribuloides seedlings inoculated with $R$. alboareolata and $A$. princeps were nearly 4 times that of the uninoculated $C$. tribuloides seedlings. The N, P and $\mathrm{K}$ contents of the $P$. kesiya seedlings inoculated with $R$. alboareolata and A. princeps were about 1.5, 2.1 and 1.7 times that of the uninoculated $P$. kesiya seedlings, respectively (Table 3 and Table 4)

Table-4. Nutrient accumulations (mg/plant) in shoots of Pinus kesiya seedlings

\begin{tabular}{|c|c|c|c|}
\hline ECM fungi & N content & P content & K content \\
\hline None & $5.22 \pm 0.27^{\mathrm{b}}$ & $0.22 \pm 0.01^{\mathrm{b}}$ & $11.73 \pm 0.64^{\mathrm{b}}$ \\
\hline R. alboareolata & $8.09 \pm 0.58^{\mathrm{a}}$ & $0.48 \pm 0.01^{\mathrm{a}}$ & $19.70 \pm 1.15^{\mathrm{a}}$ \\
\hline A. princeps & $7.90 \pm 0.24^{\mathrm{a}}$ & $0.44 \pm 0.02^{\mathrm{a}}$ & $19.13 \pm 0.47^{\mathrm{a}}$ \\
\hline
\end{tabular}

Means \pm standard error of the means in the same column with different letters are significantly different $(p \leq 0.05)$.

\section{Discussion}

Characteristics of ECM root tips can be used for preliminary investigation of ECM fungi associated with host plants. For $C$. tribuloides seedlings, features of branching patterns of ECM roots of $C$. tribuloides associated with $R$. alboareolata and $A$. princeps were irregularly pinnate. Whereas characteristics of ECM root tips of $P$. kesiya associated with $R$. alboareolata and A. princeps were dichotomous branching patterns. Most mycorrhizal root tips of Pinaceae are dichotomously branched such as $P$. radiata roots associated with Suillus brevipes, Amanita muscaria and Boletus edulis (Brundrett et al., 1996), and P. kesiya associated with Pisolithus orientalis (Kumla et al., 2016). Features of branching patterns of ECM root tips are dependent on associations of particular host plants and ECM fungi. Branching pattern of ECM roots of Eucalyptus globulus associated with Laccaria laccata was pinnate (Brundrett et al., 1996). Feature of ECM roots of Intsia bijuga associated with Scleroderma sp. was monopodial pinnate in the young ectomycorrhizal roots, but the feature of ECM roots was becoming irregular pinnate in the older ectomycorrhizal roots (Nugroho et al., 2010). Smith and Pfister (2009) reported that they found ECM roots in the form of tuberculate ECM, which was an association between Quercus sp. (Fagaceae) and Boletus rubropunctus. 
Mantle sheath hyphae of the ECM fungi that enveloped on the outside of the ECM roots could protect the roots against water loss (Smith and Read, 1997; Pietro et al, 2007; Bücking et al., 2012). Inoculation with $R$. alboareolata and A. princeps significantly increased survival of C. tribuloides seedlings. External hyphae and mantle sheath hyphae of the ECM root tips helped to increase the areas of water and nutrient uptake, which helped to increase survival and growth of $C$. tribuloides seedlings. Efficacy of ECM fungi for growth of the host plants depends on associations between ECM fungi, the host plants and environmental conditions (Brundrett et al., 1996; Smith and Read, 1997). Growth of $C$. tribuloides and $P$. kesiya seedlings was significantly increased by mycorrhization with $R$. alboareolata and A. princeps. Especially, shoot dry weight and root dry weight of $C$. tribuloides seedlings inoculated with $R$. alboareolata were higher than those of the seedlings inoculated with $A$. princeps. This experiment showed that $R$. alboareolata had high efficiency for increasing growth of $C$. tribuloides seedlings. The increase in growth of the $R$. alboareolata inoculated $C$. tribuloides seedlings were nearly two times higher than the $P$. kesiya seedlings. The efficacy of $R$. alboareolata forming ECM with $C$. tribuloides implies a more suitable association between this ECM fungus and the host plant within the nursery growing conditions.

Accumulation of nutrient contents of host plants was dependent on the associations between the ECM fungi and the seedling species (Smith and Read, 1997). Shoot nutrient contents of N, P and K in $C$. tribuloides and $P$. kesiya inoculated with $R$. alboareolata and $A$. princeps were increased. In particular, the accumulation of N, P and $\mathrm{K}$ contents in $C$. tribuloides seedlings were much greater than in $P$. kesiya seedlings. ECM fungi are known to take up both organic and inorganic nitrogen sources such as amino acids and $\mathrm{NH}_{4}{ }^{+}$from the soil and translocate to the host plants at the interface areas of Hartig net hyphae and epidermal and cortical cells (Chalot et al., 1994; Daza et al., 2006). Most of ECM fungi increase $\mathrm{P}$ uptake, especially in fungal species with external hyphae of the long-distance exploration type (Lehto and Zwiazek, 2011). Whereas some ECM fungi have been reported to increase $\mathrm{K}$ accumulation in host plants. For example, Acacia spirorbis and Eucalyptus globules inoculated with ECM Pisolithus albus increased $\mathrm{K}$ contents in shoots of the host plants (Jourand et al., 2014). Hebeloma cylindrosporum could increase $\mathrm{K}$ accumulation in Pinus pinaster in $\mathrm{K}$ deficient soil (Garcia and Zimmermann, 2014). However, some ECM fungus such as Tuber melanosporum was reported that it did not increase $\mathrm{K}$ accumulation in Quercus petraea, Q. faginea and Pinus halepensis seedlings compared with the uninoculated plants (Dominguez-Nunez et al., 2008; Garcia et al., 2014). In this experiment, the results showed that $R$. alboareolata had higher efficiency than A. princeps for $\mathrm{P}$ and $\mathrm{K}$ uptakes to $C$. tribuloides seedlings. The EMC roots formed by $R$. alboareolata and $C$. tribuloides seedlings were very effective in uptake of $\mathrm{P}$ and $\mathrm{K}$. The results of this research suggest that the inoculated seedlings may be helpful for growth and survival of the plants in the early stages of planting in degraded forest areas with the low amount of ECM fungi in natural ecosystems. However, many biotic and abiotic factors in the areas have effects on competition among ECM fungi, and these factors interact with each other may have negative or positive effects on mycorrhiza formation (Mamoun and Olivier, 1993; Kennedy, 2010).

\section{Conclusion}

The edible ECM fungi, $R$. alboareolata and $A$. princeps, associated with $C$. tribuloides and $P$. kesiya seedlings were effective in increasing the growth and $\mathrm{N}, \mathrm{P}$ and $\mathrm{K}$ accumulations of the host plants. The growth responses of the inoculated $C$. tribuloides seedlings were greater than those of the inoculated $P$. kesiya seedlings. $R$. alboareolata was more effective than A. princeps for the growth of $C$. tribuloides seedlings. There was no difference in the increase growth between $P$. kesiya seedlings inoculated with each of the fungal species. Inoculation of $C$. tribuloides and P. kesiya seedlings with mycelia of the edible ECM fungi formed specific ECM associations, which may be beneficial for reforestation.

\section{Acknowledgment}

The authors acknowledge the Thailand Science Research and Innovation (TSRI) for financial support of this research. The authors acknowledge Dr. Ampai Pornleesangsuwan, senior professional level, Forestry technical officer, Northern Silvicultural Research Center for preparation of the pine seedlings. We would like to acknowledge the Center for 
Agricultural Resource System Research for supporting the greenhouse of this research. We thank the Department of National Parks, Wildlife and Plant Conservation for permission to collect the ECM mushrooms for this research. The authors would like to thank Dr. Denis Sweatman for proofreading.

Disclaimer: None.

Conflict of Interest: None.

Source of Funding: This study was financially supported by Thailand Science Research and Innovation (TSRI), Thailand.

\section{References}

Blakesley D, Elliott S, Kuarak C, Navakitbumrung P, Zangkum S and Anusarnsunthorn V, 2002. Propagating framework tree species to restore seasonally dry tropical forest: implications of seasonal seed dispersal and dormancy. Forest. Ecol. Manage. 164: 31-38.

Brundrett M, Bougher N, Dell B, Grove $\mathrm{T}$ and Malajczuk N, 1996. Working with mycorrhizas in forestry and agriculture. ACIAR Monograph, Canberra, Australia.

Bücking H, Liepold E and Ambilwade P, 2012. The role of the mycorrhizal symbiosis in nutrient uptake of plants and the regulatory mechanisms underlying these transport processes. IntechOpen. https://www.intechopen.com/books/plantscience/the-role-of-the-mycorrhizal-symbiosisin-nutrient-uptake-of-plants-and-the-regulatorymechanisms-und.

Chalot M, Brun A, Finlay RD and Söderström B, 1994. Metabolism of $\left[{ }^{14} \mathrm{C}\right]$ glutamate and $\left[{ }^{14} \mathrm{C}\right]$ glutamine by the ectomycorrhizal fungus Paxillus involutus. Microbiol. 140: 1641-1649.

Chandrasrikul A, Suwanarit P, Sangwanit U, Morinaga $\mathrm{T}$, Nishizawa $\mathrm{Y}$ and Murakami $\mathrm{Y}$, 2008. Diversity of mushrooms and macrofungi in Thailand. Kasetsart University Press, Bangkok, Thailand.

Daza A, Manjon JL, Camocho M, Romero de la Osa L, Aguilar A and Santamaria C, 2006. Effect of carbon and nitrogen sources, $\mathrm{pH}$ and temperature on in vitro culture of several isolates of Amanita caesarea (Scop: Fr.) Per. Mycorrhiza. 16: 133136.

Dominguez-Nunez JA, Planelles GR, RodriguezBarreal JA and Saiz de Omenaca-Gonzalez JA, 2008. The effect of Tuber melanosporum Vitt. mycorrhization on growth, nutrition, and water relations of Quercus petraea Liebl., Quercus faginea Lamk., and Pinus halepensis Mill. seedlings. New Forest. 2: 159-171.

Dosskey MG, Linderman RG and Boersma L, 1990. Carbon-sink stimulation of photosynthesis in Douglas fir seedlings by some ectomycorrhizas. New Phytol. 115: 269-274.

Fern K, 2014. Tropical plant database: Useful tropical plants. http://tropical.theferns.info/viewtropical.php?id= Pinus+ kesiya.

Finlay RD, 2004. Mycorrhizal fungi and their multifunctional role. Mycologist. 18: 91-96.

Forest Restoration Research Unit, 2000. Tree seeds and seedlings for restoring forests in northern Thailand. Department of Biology, Faculty of Science, Chiang Mai University, Chiang Mai, Thailand.

Garcia K, Delteil A, Conéjéro G, Becquer A, Plassard C, Sentenac $\mathrm{H}$ and Zimmermann S, 2014. Potassium nutrition of ectomycorrhizal Pinus pinaster: overexpression of the Hebeloma cylindrosporum HcTrk1 transporter affects the translocation of both $\mathrm{K}^{+}$and phosphorus in the host plant. New Phytol. 201: 951-960.

Garcia K and Zimmermann SD, 2014. The role of mycorrhizal associations in plant potassium nutrition. Front. Plant Sci. 5: 1-9.

Jourand P, Hannibal L, Majorel C, Mengant S, Ducousso M and Lebrun M, 2014.

Ectomycorrhizal Pisolithus albus inoculation of Acacia spirorbis and Eucalyptus globulus grown in ultramafic topsoil enhances plant growth and mineral nutrition while limits metal uptake. J. Plant Physiol. 171: 164-172.

Kennedy P, 2010. Ectomycorrhizal fungi and interspecific competition: species interactions,

community structure, coexistence mechanisms, and future research directions. New Phytol. 187: 895910.

Kumla J, Suwannarach N and Lumyong S, 2016. Characterization of Pisolithus orientalis in

culture and in vitro mycorrhization with Eucalyptus camaldulensis and Pinus kesiya. Mycosphere. 7: 1415-1424.

Lehto T and Zwiazek JJ, 2011. Ectomycorrhizas and water relations of trees. Mycorrhiza. 21: 7190.

Mamoun M and Olivier JM, 1993. Competition between Tuber melanosporum and other 
ectomycorrhizal fungi under two irrigation regimes. Plant Soil. 149: 211-218.

Marx DH, 1969. The influence of ectotrophic mycorrhizal fungi on the resistance of pine roots to pathogenic infections. I. Antagonism of mycorrhizal fungi to root pathogenic fungi and soil bacteria. Phytopathol. 59: 153-163.

Nugroho JD, Mansur I, Purwito A and Suhendang E, 2010. Morphological characteristics of ectomycorrhizas on Merbau [Intsia bijuga (Colebr.) O. Kuntze.]. HAYATI J. Biosci. 17: 68-72.

Ohta A and Fujiwara N, 2003.Fruit-body production of an ectomycorrhizal fungus in genus Boletus in pure culture. Mycosci. 44: 295300 .

Pietro MD, Churin JL and Garbaye J, 2007. Differential ability of ectomycorrhizas to survive drying. Mycorrhiza. 17: 547-550.

Sanmee R, Lumyong P, Dell B and Lumyong S, 2010. In vitro cultivation and fruit body formation of the black bolete, Phlebopus portentosus, a popular edible ectomycorrhizal fungus in Thailand. Mycosci. 51: 15-22.
Schmidt LH and Nguyen DTL, 2004. Pinus kesiya Royle ex Gordon: Seed leaflet. http://curis.ku.dk/ws/files/20547020/pinuskesiya -93_int.pdf.

Smith ME and Pfister DH, 2009. Tuberculate ectomycorrhizae of angiosperms: the interaction between Boletus rubropunctus (Boletaceae) and Quercus species (Fagaceae) in the United States and Mexico. Am. J. Bot. 96: 1665-1675.

Smith SE and Read DJ, 1997. Mycoorhizal symbiosis, 2nd ed. Academic Press, London, England.

\section{Contribution of Authors}

Youpensuk S: Conceived idea, designed research methodology, collected and analysed data and article write up

Wanwaen S: Literature review, collected and analysed data and article write up 